HUMANAS E SOCIAIS

V.8 • N.3 • 2020 • Fluxo Contínuo

ISSN Digital: 2316-3801

ISSN Impresso: 2316-3348

DOI: 10.17564/2316-3801.2020v8n3p451-461
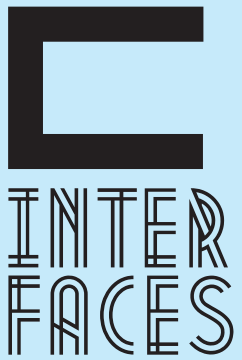

CIENTÍFICAS

\section{A UNIVERSALIZACC̃̃O DOS DIREITOS HUMANOS E O RELATIVISMO CULTURAL: IMPASSES E PERSPECTIVAS À HUMANIZAÇ̃̃OO SOCIAL}

UNIVERSALIZATION OF HUMAN RIGHTS AND

CULTURAL RELATIVISM: IMPASSES AND PROSPECTS ON SOCIAL HUMANIZATION

UNIVERSALIZACIÓN DE LOS DERECHOS HUMANOS Y EL RELATIVISMO CULTURAL: IMPASOS Y PERSPECTIVAS SOBRE LA HUMANIZACIÓN SOCIAL
Ariane Faverzani da $L \mathrm{uz}^{1}$ Ariele Faverzani da $\mathrm{Luz}^{2}$ Janaína Faverzani da Luz Alex Faverzani da Luz ${ }^{4}$

\section{RESUMO}

As controvérsias existentes entre a universalização dos direitos humanos e o relativismo cultural são merecedoras de análise no âmbito jurídico, tendo em vista a necessidade de se discutir se é possível estabelecer direitos humanos mínimos que sejam universais, apesar de existirem inúmeras tradições culturais distintas perpetradas pelos grupos sociais que se intensificam com o processo de globalização. Ainda, faz-se imperativo abordar se os Estados estão impelidos a garantir estes direitos, mesmo sendo detentores de soberania, correndo o risco de seu cumprimento se sobrepor à cultura local. Nesse sentido, este artigo, de cunho bibliográfico, objetivou realizar uma concisa análise da universalização dos direitos humanos e do relativismo cultural sob a perspectiva da humanização social. Os seus resultados indicaram a necessidade de um diálogo intercultural em uma democracia deliberativa para a definição de valores mínimos que devem ser tidos como universais, considerando os impactos da globalização e do multiculturalismo. Além disso, os Estados, apesar de detentores de soberania, são os responsáveis por zelar pelo cumprimento dos direitos universais em defesa de um mínimo ético irredutível e da concessão de uma vida digna às pessoas.

\section{PALAVRAS-CHAVE}

Direitos Humanos. Multiculturalismo. Relativismo Cultural. Universalismo. 


\section{ABSTRACT}

The controversies between the universalization of human rights and cultural relativism are worthy of legal analysis, considering the need to discuss whether it is possible to establish universal minimum human rights, although there are numerous distinct cultural traditions perpetrated by social groups that are intensifying with the process of globalization. Still, it is imperative to address whether States are compelled to guarantee these rights, even if they are sovereign and risk compliance with the local culture. In this sense, this bibliographic article aimed to conduct a concise analysis of the universalization of human rights and cultural relativism from the perspective of social humanization. Their results indicated the need for an intercultural dialogue in a deliberative democracy to define minimum values that should be taken as universal, considering the impacts of globalization and multiculturalism. In addition, States, while sovereign holders, are responsible for enforcing universal rights in defense of an irreducible ethical minimum and the granting of a dignified life to the people.

\section{DESCRIPTORS}

Human Rights. Multiculturalism. Cultural Relativism. Universalism.

\section{RESUMEN}

Las controversias entre la universalización de los derechos humanos y el relativismo cultural merecen un análisis legal, considerando la necesidad de discutir si es posible establecer derechos humanos mínimos universales, aunque existen numerosas tradiciones culturales distintas perpetradas por grupos sociales que se intensifican con el proceso de globalización. Todavía, es imprescindible abordar si los Estados están obligados a garantizar estos derechos, incluso si son soberanos y corren el riesgo de cumplir con la cultura local. En este sentido, este artículo bibliográfico tuvo como objetivo realizar un análisis conciso de la universalización de los derechos humanos y el relativismo cultural desde la perspectiva de la humanización social. Sus resultados indicaron la necesidad de un diálogo intercultural en una democracia deliberativa para definir valores mínimos que deberían tomarse como universales, considerando los impactos de la globalización y el multiculturalismo. Además, los Estados, aunque titulares soberanos, son responsables de hacer cumplir los derechos universales en defensa de un mínimo ético irreducible y de otorgar una vida digna a la gente. 


\section{DESCRIPTORES}

Derechos Humanos. Multiculturalismo. Relativismo Cultural. Universalismo.

\section{INTRODUCÇÃO}

A discussão sobre a universalização dos direitos humanos e o relativismo cultural constitui um dos temas mais relevantes na esfera do direito internacional, visto que cada um possui argumentos que se contrapõem quanto à aplicação e ao reconhecimento dos direitos humanos. A dificuldade em definir quais são as posições que devem predominar não se refere apenas ao que é o ideal a ser empregado nas relações internacionais, já que não é possível retirar a legitimidade de nenhuma das correntes, mas, sim, quais serão as supressões que se sucederão a partir disso.

Nesse contexto, questiona-se se os direitos humanos possuem abrangência universal e se são capazes de estabelecer direitos mínimos aos indivíduos, bem como se os Estados estão obrigados a garanti-los. Além disso, interroga-se se a existência de direitos internacionais deve se sobrepor ao multiculturalismo ou se a soberania dos Estados relativiza a intervenção internacional. Tais indagações são de suma relevância e merecem ser consideradas ao se abordar a temática dos direitos humanos.

Assim, o presente ensaio científico busca analisar a universalização dos direitos humanos e o relativismo cultural, sob a ótica da humanização social, por meio de uma concisa revisão bibliográfica. Para tanto, em um primeiro momento, apresenta o contexto histórico em que surgiu a necessidade de definição dos direitos baseados na dignidade da pessoa humana e a concepção trazida pelo universalismo. Em seguida, expõe os apontamentos do relativismo cultural, tendo em vista os efeitos da globalização e do multiculturalismo, bem como as ambiguidades e as possibilidades de ambas as posições.

\section{A UNIVERSALIZAÇ̃̃O DOS DIREITOS HUMANOS: A DIGNIDADE DA PESSOA HUMANA COMO FUNDAMENTO PARA A NÃO VIOLAÇÃO DE DIREITOS}

A internacionalização dos direitos humanos ocorreu após a Segunda Guerra Mundial, tendo sua motivação no genocídio nazista praticado por meio de atos brutais e cruéis pelo ditador Adolf Hitler, que culminaram na violação dos direitos humanos daqueles que não pertenciam à raça ariana, a qual era considerada superior às demais e, portanto, a única detentora de direitos. Nas palavras de Piovesan (2013, p. 191), "apresentando o Estado como o grande violador de direitos humanos, a Era Hitler foi marcada pela lógica da destruição e da descartabilidade da pessoa humana, o que resultou no extermínio de onze milhões de pessoas".

Diante disso, desde 1945, reconhece-se a universalidade e a inclusividade dos direitos humanos, tendo sido afastada, ao menos teoricamente, a ideia de que são aplicados em favor dos privi- 
legiados e de que são dotados de um caráter de exclusividade. No entanto, a Declaração Universal dos Direitos do Homem era vista como limitada, pois apesar de prever diversos direitos aos indivíduos, não impunha formas de execução que deveriam ser seguidas pelos Estados nem órgãos fiscalizadores de sua aplicabilidade. Assim, desde 1946, a Organização das Nações Unidas (ONU) corrigiu as falhas e alterou as dimensões da referida Declaração por meio da criação da Declaração Universal dos Direitos Humanos de 1948, especificando, dentre outros acréscimos, as obrigações que deveriam ser exercidas pelos Estados e estabelecendo organismos de controle de cumprimento dos direitos humanos (MBAYA, 1997, p. 18-19).

Desse modo, a Declaração Universal dos Direitos Humanos de 1948, fundamentando-se no reconhecimento da dignidade da pessoa humana, busca estabelecer valores mínimos que devem ser tidos como universais, culminando em uma ética global a ser seguida pelos Estados, independentemente de crenças religiosas, de costumes ou da cultura adotada por cada país (PIOVESAN, 2013, p. 204205). Nesse viés, o seu artigo $2^{\circ}$, corrobora o exposto ao referir que todas as pessoas podem recorrer aos direitos e às liberdades previstas na Declaração, não havendo nenhuma objeção de raça, de cor, de sexo, de língua, de religião, de opinião política ou outra, de origem nacional ou social, de fortuna, de nascimento ou de qualquer outra circunstância.

Salienta-se, ainda, que não será admitida nenhuma diferença de cunho político, jurídico ou internacional referente ao país ou ao território de naturalidade do indivíduo, ainda que esse país ou território seja independente, esteja sob tutela, seja autônomo ou esteja submetido a alguma restrição em sua soberania (ONU, 1948).

Assim, vislumbra-se que a teoria dos direitos humanos deve perpassar por uma análise bidimensional no que tange à teoria jurídica - a qual verifica os tratados, as convenções e as legislações relacionados ao tema e os organismos nacionais e internacionais responsáveis por garantir a eficácia desses direitos - bem como no que se refere à apreciação de seus fundamentos (BARRETO, 2004, p. 280). Nesse sentido, Barreto (2004, p. 280) aponta a necessidade de vincular a análise teórica e prática na teoria dos direitos humanos:

[...] não teria sentido a análise teórica, abstrata, que não levasse em consideração os problemas reais que afetam quotidianamente a pessoa humana neste final de século (discriminações sociais, políticas e religiosas, falta de liberdade, limpeza étnica, miséria, analfabetismo etc.) e, nem também, aceitar como verdade última, universal e acabada, as diversas situações sociais do mundo contemporâneo. Torna-se, portanto, irrelevante o argumento de que a prática é o que importa na avaliação dos direitos humanos, pois esta se acha vinculada a argumentos teóricos, que sempre impulsionaram a implementação histórica dessa categoria de direitos.

A concepção universalista propõe a criação de uma norma absoluta que estabeleça direitos universais, partindo da lógica de que existem direitos que devem ser garantidos a todos os seres humanos, independentemente da cultura adotada no país que vivem, pois se faz necessário estipular um mínimo ético irredutível. Nesse contexto, “o sentimento de afeição, a necessidade de cooperação 
encontrada em todas as culturas, a identificação do lugar na comunidade e a ajuda para quem se encontra em necessidade [...]" (BARRETO, 2004, p. 286) exemplificam características semelhantes a todos os indivíduos que inviabilizam a relativização dos direitos humanos. Dessa forma, o universalismo “[...] flexibiliza as noções de soberania nacional e jurisdição doméstica, ao consagrar um parâmetro internacional mínimo, relativo à proteção dos direitos humanos, aos quais os Estados devem se conformar" (PIOVESAN, 2013, p. 211).

Os direitos universais são construídos por meio da observação de inúmeras realidades sociais, sendo que o monismo moral não pode interferir na definição desses direitos, visto que é possível determinar características análogas aos indivíduos que fundamentam uma sociedade baseada na solidariedade. Por conseguinte, a descoberta das características semelhantes pode ser obtida mediante um diálogo entre as culturas, realizado em um modelo de democracia deliberativa, a qual permite a construção de uma discussão no espaço público pelos sujeitos (BARRETO, 2004, p. 284).

Quanto à democracia deliberativa, Benhabib (2007, p. 48) assevera que se trata de um modelo que organiza a legitimidade pública e coletiva

[...] nas principais instituições de uma sociedade com base no princípio segundo o qual as decisões que atingem o bem-estar de uma coletividade podem ser vistas como o resultado de um procedimento de deliberação livre e racional entre indivíduos considerados iguais política e moralmente.

Além disso, a necessidade de expor as suas opiniões em público faz com que os indivíduos reflitam se as suas preferências individuais são benéficas ao âmbito social ou se abarcam apenas interesses particulares (BENHABIB, 2007, p. 54).

De forma similar, Santos (2004, p. 250) indica a necessidade de se formalizar uma concepção multicultural de direitos humanos, baseada em um diálogo intercultural, o que fomentaria uma relação equilibrada entre os poderes globais e locais:

[...] os direitos humanos têm de ser reconceptualizados como multiculturais. Concebidos como direitos universais, como tem sucedido, os direitos humanos tenderão sempre a ser um instrumento do "choque de civilizações". [...] A sua abrangência global será obtida à custa da sua legitimidade local. A relação equilibrada e mutuamente potenciadora entre a competência global e a legitimidade local, que, em meu entender, é a pré-condição de uma política contra-hegemônica de direitos humanos no nosso tempo, exige que estes sejam transformados à luz do que designo por multiculturalismo emancipatório [...].

Nesse sentido, o próprio artigo $2^{\circ}$, da Declaração Universal dos Direitos Humanos, já mencionado anteriormente, reafirma a ideia universalista, não admitindo que particularismos se sobreponham à sua aplicação. Também, a Declaração de Viena, adotada em 25 de junho de 1993, ratifica a posição universalista quando enfatiza, em seu parágrafo $5^{\circ}$, a universalidade, a indivisibilidade, a interdependência e a inter-relação dos direitos humanos, bem como quando aponta que os direitos humanos devem ser vistos e utilizados em uma esfera global de modo justo e igualitário e devem predominar 
sob os sistemas políticos, econômicos e culturais dos Estados, os quais necessitam ser garantidos e protegidos (CONFERÊNCIA..., 1993).

Assim sendo, os universalistas não desconsideram as peculiaridades e as diversas moralidades dos Estados, mas defendem que a diversidade cultural deve contribuir para enriquecer os direitos humanos e não ser utilizada para justificar o seu descumprimento, uma vez que são inerentes a toda pessoa humana, transcendem diferenças geográficas e históricas, visam impedir que novas violações de direitos humanos ocorram e que se repitam os horrores praticados no holocausto. Ao legitimar a defesa de práticas intoleráveis que atentam aos direitos dos indivíduos na cultura aceita e repercutida no seio social, prevalece um discurso autoritário que oprime as garantias sociais, impedindo o direito das pessoas de serem reconhecidas como sujeitos de direitos.

Ainda, salienta-se que "[...] se diversos Estados optaram por ratificar instrumentos internacionais de proteção dos direitos humanos, é porque consentiram em respeitar tais direitos, não podendo isentar-se do controle da comunidade internacional na hipótese de violação desses direitos [....]" (PIOVESAN, 2013, p. 213). Por fim, os direitos humanos representam o que é

[] natural, común o universal a todos los individuos. Constituyen una construcción teórica (principalmente teórico-jurídica) basada en un modelo de sujeto (de Derecho) que se abstrae de las particularidades jurídicamente irrelevantes de cada cual para señalar las similitudes relevantes []. (GARCIA; REAL, 2000, p. 22).

\section{RELATIVISMO CULTURAL: A INFLUÊNCIA DA GLOBALIZAÇ̃̃O E DO MULTICULTURALISMO NO RECONHECIMENTO DOS DIREITOS HUMANOS}

O conceito de globalização deve ser compreendido em um sentido amplo, uma vez que o termo não se restringe apenas ao capitalismo financeiro, mas influencia diferentes âmbitos da vida humana. Dessa maneira, Santos (2004, p. 244) corrobora o exposto ao ensinar que o vocábulo não deve se ater a sua singularidade, pois há inúmeras formas de globalizações:

Aquilo que habitualmente designamos por globalização são, de fato, conjuntos diferenciados de relações sociais; diferentes conjuntos de relações sociais dão origem a diferentes fenômenos de globalização. Nestes termos, não existe estritamente uma entidade única chamada globalização; existem, em vez disso, globalizações. Em rigor, este termo só deveria ser usado no plural.

Assim, a globalização se constitui em um processo de integração entre os países que abrange os aspectos econômico, social, cultural, religioso e político, sendo que seus reflexos impactam consideravelmente na violação dos direitos humanos já que estes são afetados pelas exigências da sociedade e reproduzem as prioridades determinadas socialmente. 0 avanço da globalização provoca, 
portanto, a violação “[...] dos direitos em benefício da produtividade, o sequestro da democracia em aras de mercado e a usurpação da política pelas forças econômicas" (JULIOS-CAMPUZANO, 2008, p. 97). Além disso, "[...] a globalização incontrolada contribui, ainda, para uma separação dentro das sociedades em níveis nacionais e internacionais, agravando a distância entre países ricos e pobres" (MAZZA; COSTA, 2016, p. 396).

Quanto ao multiculturalismo, este pressupõe a existência de tradições culturais distintas perpetradas pelos grupos sociais que se intensificam com o processo de globalização, o que ocasiona dificuldades ao se abordar a universalidade dos direitos humanos (MAZZA; COSTA, 2016, p. 399). Segundo a Declaração Universal sobre a Diversidade Cultural, as múltiplas culturas são necessárias para o gênero humano e, por isso, são patrimônio comum da humanidade, bem como a defesa do pluralismo cultural é um dever ético que se relaciona à dignidade humana. No entanto, o artigo $4^{\circ}$, da citada Declaração, ressalta que a diversidade cultural não pode ser utilizada como justificativa para a violação e/ou limitação dos direitos humanos garantidos na esfera internacional (UNESCO, 2002).

Dessa forma, o relativismo cultural supõe que a existência de múltiplas culturas na sociedade, compostas de distintos valores, hábitos e práticas sociais, impossibilita a definição de direitos universais aos indivíduos, pois não há como um direito atender ao bem-estar de todos os seres humanos, tendo em vista que estes não se assemelham, inviabilizando generalizações (BARRETO, 2004, p. 284). Para os relativistas,

[...] o que consideramos hoje como universal é o fundacional do ocidente transformado em universal. A hegemonia [...] do ocidente nos últimos cinco séculos conseguiu transformar o que era (ou se supunha ser) único e específico desta região do mundo em algo universal e geral (SANTOS; CHAUI, 2013, p. 58).

Contudo, a Declaração Universal dos Direitos Humanos de 1948 não foi influenciada apenas pela ideologia ocidental, visto que na sua formulação houve a participação de representantes de outros sistemas. Assim, a Assembleia Geral das Nações Unidas, em 1977, ressaltou a importância da participação dos países desenvolvidos e em desenvolvimento nas atividades relacionadas aos direitos humanos, devendo suas manifestações serem analisadas. Portanto, é possível aludir que a tradição ocidental foi ultrapassada pela elaboração dos atuais direitos humanos no plano internacional, não prosperando a ideia de prevalência dos interesses exclusivos dos países ocidentais (MBAYA, 1997, p. 26).

Nesse contexto, Piovesan (2013, p. 211) acrescenta que o relativismo cultural vincula o direito “[...] ao sistema político, econômico, cultural, social e moral vigente em determinada sociedade. Sob esse prisma, cada cultura possui seu próprio discurso acerca dos direitos fundamentais, que está relacionado às específicas circunstâncias culturais e históricas de cada sociedade”. Além disso, “a constatação de que entre os grupos sociais existem tradições culturais múltiplas, representa para o relativismo a prova de que é impossível o estabelecimento de normas universais de comportamento social” (BARRETO, 2004, p. 285). Também, defendem a não intercessão nas tradições culturais dos Estados em respeito à prevalência do princípio da tolerância, não sendo admitido que uma cultura se sobreponha a outra (CULLETON; BRAGATO; FAJARDO, 2009, p. 236). 
Ainda, a ideia relativista, segundo a concepção social e filosófica atual, afirma que há três tipos de relativismos, os quais se subdividem em relativismo antropológico, relativismo epistemológico e relativismo cultural. 0 relativismo antropológico alude que há várias formas de vivência nos grupos sociais que irão justificar a teoria do pluralismo cultural. Entretanto, algumas necessidades humanas são universais e não locais, as quais podem ser categorizadas como imprescindíveis à coletividade. Já o relativismo epistemológico assevera a impossibilidade de se produzir um discurso ético universal que se constitua entre culturas distintas. Por fim, o relativismo cultural alega que as particularidades culturais influenciam na formalização dos valores na sociedade sob a perspectiva dos direitos humanos (BARRETO, 2004, p. 285).

Ressalta-se que no contexto de uma cultura local também existem divergências sobre a interpretação oficial da tradição religiosa ou cultural. Dessa forma, afirma-se que todas as culturas são pluralistas na medida em que o conceito de pluralismo defende que há inúmeras formas de compreensão no que tange ao legado cultural de uma sociedade. A mutilação genital feminina exemplifica esta questão ao se constatar grupos sociais que se opõem a esta prática adotada pelo seu país de origem por meio de protestos, que possuem como finalidade a garantia dos direitos humanos e a manifestação de valores que são comuns aos indivíduos, porém atualmente negados pelo poder local (BARRETO, 2004, p. 286).

Assim sendo, a discussão sobre o fundamento dos direitos humanos se intensificou a partir do momento que a ocorrência de violações culminou em uma interpretação relativista, gerando insegurança nas relações entre os Estados e na própria sociedade (BARRETO, 2004, p. 291). Por conseguinte, revela-se oportuno considerar a predominância de princípios éticos comuns à coletividade que, prezando a diversidade cultural, devem servir para resgatar o fundamento dos direitos universais e impedir que reiteradas violações se sucedam, causando a infringência de garantias mínimas.

\section{CONCLUSÃO}

A consolidação dos direitos humanos em âmbito internacional se sucedeu após a Segunda Guerra Mundial, período em que ocorreram inúmeras violações aos direitos dos indivíduos que não pertenciam à raça ariana. Assim, a partir da Declaração Universal dos Direitos Humanos de 1948, fundamentada na dignidade da pessoa humana, os direitos humanos deixaram de ser exclusivos a um grupo de pessoas para se tornarem universais, sendo capazes de proteger todos os sujeitos, sem qualquer distinção.

Nesse viés, o embate entre a universalização dos direitos humanos e o relativismo cultural é desafiador, uma vez que ambos representam a opinião de diferentes grupos sociais. Assim, a ótica universalista surge do individualismo, priorizando a liberdade e a autonomia individual para, posteriormente, abarcar a sociedade, enquanto o relativismo parte da ideia da coletividade, pressupondo que o sujeito a integra.

Diante disso, a alegação de que o universalismo pretende uniformizar as tradições e as culturas ou estabelecer uma moralidade universal não se mostra exitosa, pois o que se busca é preservar direitos mínimos a todos os indivíduos, os quais são sujeitos de direitos independentemente do contexto em 
que estão inseridos. Sabe-se que muitas pessoas não concordam com as práticas culturais de seu país e, por isso, não podem ser compelidas a sofrê-las ou a executá-las, sendo esse cenário o ideal para o surgimento dos direitos universais como um mecanismo de proteção aos indivíduos e como forma de impedir que os atos de um Estado autoritário se sobressaiam.

Portanto, os direitos humanos necessitam se pautar em um diálogo intercultural realizado em um modelo de democracia deliberativa a fim de definir valores universais mínimos, considerando os impactos da globalização e do multiculturalismo. Ademais, tendo em vista que tais direitos são dignos de respeito na esfera internacional, torna-se imperativo a sua garantia pelos Estados que, apesar de deterem soberania, devem prezar pela sua custódia em defesa de um mínimo ético irredutível e da concessão de uma vida digna às pessoas.

\section{REFERÊNCIAS}

BARRETO, Vicente de Paulo. Multiculturalismo e direitos humanos: um conflito insolúvel? In: BALDI, César Augusto (org.). Direitos humanos na sociedade cosmopolita. Rio de Janeiro: Renovar, 2004. p. 279-307.

BENHABIB, Sheyla. Sobre um modelo deliberativo de legitimidade democrática. In: WERLE, Denilson Luis; MELO, Rúrion Soares (org. e trad.). Democracia deliberativa. São Paulo: Editora Singular, Esfera Pública, 2007. p. 47-79.

CONFERÊNCIA Mundial Sobre Direitos Humanos. Declaração e programa de ação de Viena, 1993. Disponível em: https://www.oas.org/dil/port/1993\%20Declara\%C3\%A7\%C3\%A30\%20e\%20 Programa\%20de\%20Ac\%C3\%A7\%C3\%A30\%20adoptado\%20pela\%20Confer\%C3\%AAncia\%20 Mundial\%20de\%20Viena\%20sobre\%20Direitos\%20Humanos\%20em\%20junho\%20de\%201993. pdf. Acesso em: 27 jul. 2019.

CULLETON, Alfredo; BRAGATO, Fernanda Frizzo; FAJARDO, Sinara Porto. Curso de direitos humanos. São Leopoldo: Unisinos, 2009.

GARCÍA, José Antonio López; REAL, J. Alberto del. Los derechos: entre la ética, el poder y el derecho. Madrid: Dykinson, 2000.

JULIOS-CAMPUZANO, Afonso de. Os desafios da globalização: modernidade, cidadania e Direitos Humanos. Tradução de Clovis Gorczevski. Santa Cruz do Sul: Edunisc, 2008.

MAZZA, Willame Parente; COSTA, Marcelo Cacinotti. Multiculturalismo: entre o universalismo e o relativismo dos direitos humanos. Revista Jurídica da Presidência, Brasília, v. 18, n. 115, p. 387408, jun./set. 2016. 
MBAYA, Ettiene-Richard. Gênese, Evolução e Universalidade dos Direitos Humanos frente à Diversidade de Culturas. Revista Estudos Avançados, São Paulo, v. 30, n. 11, p. 17-41, 1997.

ONU - Organização das Nações Unidas. Declaração universal dos direitos humanos, 1948. Disponível em: https://www.ohchr.org/EN/UDHR/Documents/UDHR_Translations/por.pdf. Acesso em: 27 jul. 2019.

PIOVESAN, Flávia. Direitos humanos e o direito constitucional internacional. 14. ed. rev. e atual. São Paulo: Saraiva, 2013.

SANTOS, Boaventura de Sousa; CHAUI, Marilene. Direitos humanos, democracia e desenvolvimento. São Paulo: Cortez, 2013.

SANTOS, Boaventura de Sousa. Por uma concepção multicultural de direitos humanos. In: BALDI, César Augusto (org.). Direitos humanos na sociedade cosmopolita. Rio de Janeiro: Renovar, 2004. p. 239-277.

UNESCO - Organização das Nações Unidas para a Educação, a Ciência e a Cultura. Declaração universal sobre a diversidade cultural. 2002. Disponível em: http://unesdoc.unesco.org/ images/0012/001271/127160por.pdf. Acesso em: 29 jul. 2019. 
1 Especialista em Ciências Criminais pela Fundação Escola Superior do Ministério Público do Rio Grande do Sul - FMP/ RS e em Direito Civil e Processo Civil pela Faculdade Meridional - IMED; Graduada em Direito pela Faculdade Meridional - IMED; Mestranda em Direito pela Universidade de Passo Fundo - UPF com auxílio CAPES; Pós-graduanda em Direito Público pela Fundação Escola Superior do Ministério Público do Rio Grande do Sul - FMP/RS; Advogada. E-mail: arianefaverzani@outlook.com

2 Especialista em Avaliação e Diagnóstico Psicológico pela Faculdade Meridional - IMED; Pós-graduanda em Neuropsicologia pela Universidade de Araraquara (UNIARA); Graduada em Psicologia pela Faculdade Meridional - IMED; Psicóloga na Prefeitura Municipal de Marau/RS.

E-mail: arielefl@outlook.com

3 Mestra em Direito pela Universidade Regional Integrada do Alto Uruguai e das Missões - URI com auxílio CAPES; Graduada em Direito pela Faculdade Anhanguera de Passo Fundo/RS; Doutoranda em Ciências Sociais pela Universidade do Vale do Rio dos Sinos - UNISINOS; Professora no Centro de Ensino Superior Riograndense - CESURG. E-mail: jana_fl@hotmail.com

4 Doutor em História das Sociedades Ibéricas e Americanas pela Pontifícia Universidade Católica do Rio Grande do Sul - PUC/RS com auxílio CNPq; Mestre em Direito pela Universidade de Lisboa - UL e em História pela Universidade de Passo Fundo - UPF com auxílio CAPES; Especialista em História do Direito e do Pensamento Político pela Universidade de Lisboa - UL; Licenciado em História pelo Centro Universitário Leonardo da Vinci; Graduado em Direito pela Universidade de Passo Fundo - UPF. Professor do Instituto Federal de Mato Grosso - IFMT.

E-mail: alexfaverzani@hotmail.com
Recebido em: 11 de Agosto de 2019

Avaliado em: 8 de Fevereiro de 2020

Aceito em: 26 de Outubro de 2020

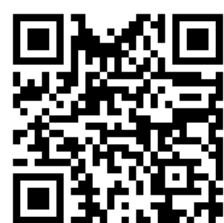

A autenticidade desse artigo pode ser conferida no site https://periodicos. set.edu.br

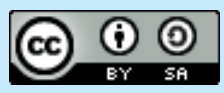

Este artigo é licenciado na modalidade acesso aberto sob a Atribuição-Compartilha Igual CC BY-SA GRUPO
TIRADENTES
Inspirando o futuro

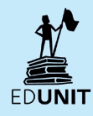

